\title{
OPTIMUM ANALYSIS OF OUTRIGGER-BRACED STRUCTURES WITH NON- UNIFORM CORE AND MINIMUM TOP-DRIFT
}

\author{
M. F. Cheok ${ }^{1}$, C. C. Lam², G. K. Er ${ }^{3}$
}

${ }^{1}$ Department of Civil and Environmental Engineering, Faculty of Science and Technology at the University of Macau, Macau SAR, P.R. China (da82735@umac.mo)

${ }^{2}$ Department of Civil and Environmental Engineering, Faculty of Science and Technology at the University of Macau, Macau SAR, P.R. China

${ }^{3}$ Department of Civil and Environmental Engineering, Faculty of Science and Technology at the University of Macau, Macau SAR, P.R. China

\begin{abstract}
The optimum locations of the outriggers are analyzed for the outrigger-braced structure with the core being uniform in sections throughout the height of the structure. The analysis is carried out with the flexibility method by considering the compatibility of the column's axial de-formation. The optimum objective aims at reducing the top-drift by finding the locations of the outriggers. The procedure of optimum analysis for the outrigger-braced structure is presented in detail in the paper. Various lateral loading cases are considered in the analysis, including uniformly distributed loading, triangularly distributed loading, and the loading with parabolic distribution. The influences of various structure parameters such as the flexural stiffness of core, outriggers, and columns are all discussed. Numerical results are presented and discussed. The results for the structures with different number of outriggers are given. Eventually, the efficiency analyses are also given with the determined optimum locations. The results between the structures with non-uniform core and uniform core are compared to show their difference of the optimum locations of the outriggers, and relevant efficiencies in reducing the top-drift.
\end{abstract}

Keywords: optimum locations of outriggers, non-uniform core, core-moment and top-drift reduction.

\section{INTRODUCTION}

Among numerous structures resisting lateral forces, outrigger-braced structure is one of the typical structures popularly employed in tall building design. It basically possesses three components: a reinforced concrete shear wall or braced steel core frame, flexural cantilevers or outriggers, and exterior columns. Generally, the core and exterior columns are connected to the outriggers respectively at several levels, which forms a structure to resist lateral 
force efficiently. The analysis for the preliminary design of the outrigger-braced structure was initially given by Smith and Salim in 1981 [2]. In their studies, the sectional stiffness of the core is assumed to be uniform over the entire height. In real structural design, the sectional stiffness of the core may not be uniform in tall building design. In this paper, the sectional properties of the core and columns are assumed to be varied at different levels so as to fulfill the more real situation. In this study, the governing equations for the optimum locations of outriggers and top-drift reduction efficiency under various lateral loads are formulated based on the idea presented by Er and Iu in [1]. In addition, the influence of the relative stiffness parameters on the structural behavior at different levels is investigated. Numerical results obtained with non-uniform core will be presented and compared to numerical results obtained with uniform core.

\section{GOVERNING EQUATIONS ON STRUCTURE WITH UNIFORM CORE AND COLUMN}

The study on the outrigger-braced structure for preliminary design of the structure was based on the following assumptions [2]: a) The structure behaves linear elastically; b) The major structural components of core, columns and outriggers are flexural rigid; c) Only axial forces are induced in the exterior columns; d) Outriggers are rigidly attached to the core while the core is rigidly connected to the base; e) The sectional properties of the core and column remain uniform over the entire height. Generally, assumptions a) to d) are reasonable in preliminary design under lateral loads. However, the last assumption is not valid to most of the tall buildings as the sizes of core and columns are generally reduced along the structure height.

Consider a simplified uniform core structure with n outriggers under uniform distributed lateral load, as shown in Fig 1.

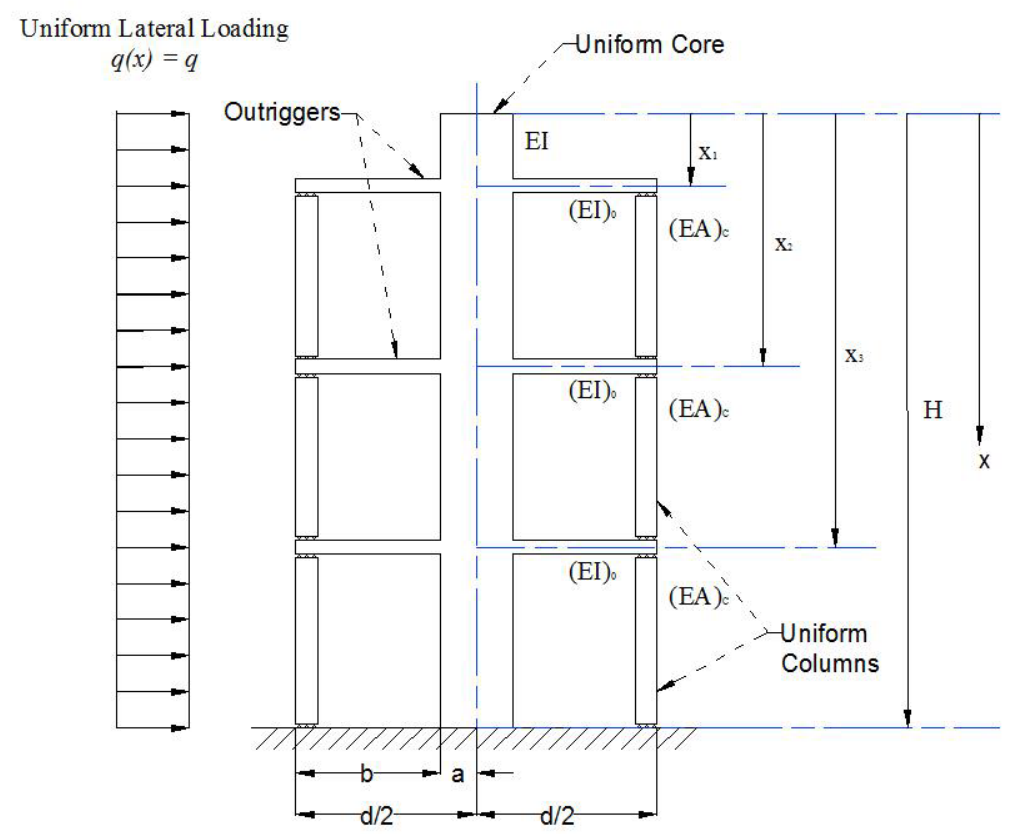

Figure 1. Outrigger braced structure with material and dimensional parameters 
In Fig. 1, $E I$ is the flexural rigidity of the core; $(E I)_{0}$ is the effective flexural rigidity of the outriggers; $E A$ is the axial rigidity of the exterior column; $H$ is the entire height of the core; $d / 2$ is horizontal distance between centroid of core and exterior column; $q$ is the lateral loading; $N_{i}$ is the axial force in the column between $\mathrm{i}^{\text {th }}$ and $(\mathrm{i}+1)^{\text {th }}$ level of outriggers. $y_{i}=\frac{x_{i}}{H}$ is the relative location of the $\mathrm{i}^{\text {th }}$ outrigger with $x_{i}$, being the distance between the $\mathrm{i}^{\text {th }}$ outrigger and the top of structure; $\omega=\frac{s_{1}}{s H}$ is the relative rigidity of core-column system and outriggers with $s=\frac{1}{E I}+\frac{2}{d^{2}(E A)_{c}}$ and $s_{1}=\frac{d}{12(E I)_{0}} ; \alpha=\frac{2 E I}{d^{2}(E A)_{c}}$ is the relative rigidity between core and column. Aiming at minimizing the top-drift, the optimum levels of outriggers can be located by solving the equations formulated by setting the derivative of $\Delta_{0}$ in Eq. (1) with respect to $y_{j}$ to zero. It is noted that the optimum values of the outriggers are mainly influenced by the relative rigidity parameter $\omega$. The following equations were obtained for the structure with uniform core under uniform lateral loading with the compatibility of the axial deformation of columns [1].

$$
\Delta_{0}=\frac{q H^{4}}{8 E I}-\frac{d H^{2}}{2 E I} \sum_{i=1}^{n} N_{i}\left(y_{i+1}^{2}-y_{i}^{2}\right)=\frac{q H^{4}}{8 E I}\left\{1-\frac{2}{3(\alpha+1)}\left\{B_{\text {ou }}\right\}\left[A_{o}\right]^{-1}\left\{D_{o}\right\}\right\}
$$

where

$$
\begin{aligned}
& {\left[A_{o}\right]=\left[\begin{array}{cccccc}
2 \omega+\left(y_{2}-y_{1}\right) & -\omega & \cdots & 0 & \cdots & 0 \\
-\omega & 2 \omega+\left(y_{3}-y_{2}\right) & \cdots & 0 & \cdots & 0 \\
\vdots & \vdots & \ddots & \vdots & & \vdots \\
0 & 0 & \cdots & 2 \omega+\left(y_{i+1}-y_{i}\right) & \cdots & 0 \\
\vdots & \vdots & & \vdots & \ddots & \vdots \\
0 & 0 & \cdots & 0 & \cdots & \omega+\left(1-y_{n}\right)
\end{array}\right]} \\
& \left\{B_{o u}\right\}^{T}=\left[\begin{array}{c}
y_{2}^{3}-y_{1}^{3} \\
y_{3}^{3}-y_{2}^{3} \\
\vdots \\
y_{i+1}^{3}-y_{i}^{3} \\
\vdots \\
1-y_{n}^{3}
\end{array}\right] \\
& \left\{D_{o}\right\}=\left[\begin{array}{c}
y_{2}^{2}-y_{1}^{2} \\
y_{3}^{2}-y_{2}^{2} \\
\vdots \\
\left(1-y_{n}^{2}\right)
\end{array}\right]
\end{aligned}
$$




\section{GOVERNING EQUATIONS ON STRUCTURE WITH NON-UNIFORM CORE AND COLUMN}

For a more realistic model, the assumption e) mentioned above is replaced by: The moment inertia of core and the sectional area of columns vary simultaneously between different outrigger levels of the structure. Therefore, the parameter $k_{i}$, about the relative sectional stiffness of core and column between $\mathrm{i}^{\text {th }}$ and $(\mathrm{i}+1)^{\text {th }}$ level of outriggers is introduced in the this study. The value of this parameter is assigned to be 1 for the bottom portion and reduces for the above portions linearly or quadratically. The structure of non-uniform core-column system with n outriggers under uniformly distributed lateral load is demonstrated in Fig. 2.

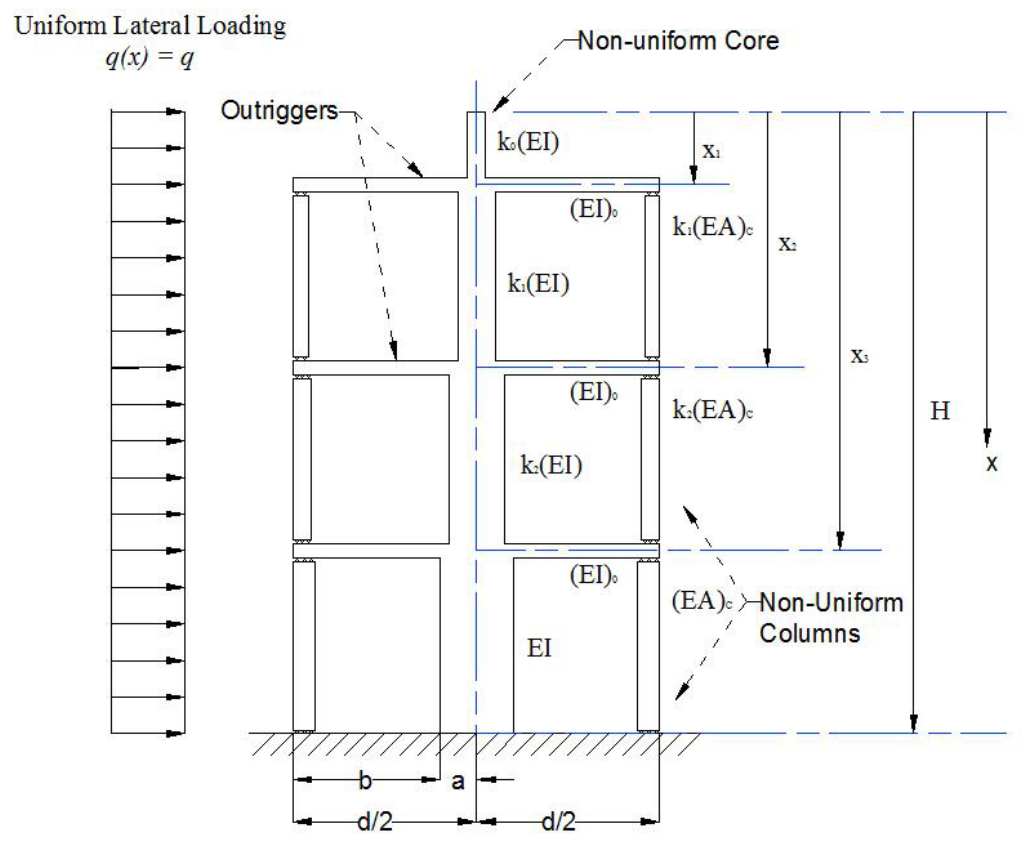

Figure 2. Outrigger-braced structure with non-uniform core and column 
The top-drift equation of non-uniform structure and uniformly lateral load can be formulated with the flexibility method to be:

$$
\Delta_{0}=\frac{q H^{4}}{8 E I}\left(\frac{y_{1}^{4}}{k_{0}}+\sum_{i=1}^{n} \frac{y_{i+1}^{4}-y_{i}^{4}}{k_{i}}\right)-\frac{d H^{2}}{2 E I} \sum_{i=1}^{n} \frac{N_{i}\left(y_{i+1}^{2}-y_{i}^{2}\right)}{k_{i}}=\frac{q H^{4}}{8 E I}\left\{C_{1}-\frac{2}{3(\alpha+1)}\left\{B_{N u}\right\}\left[A_{N}\right]^{-1}\left\{D_{N}\right\}\right\}
$$

where

$$
\begin{aligned}
& {\left[A_{N}\right]=\left[\begin{array}{ccccccc}
2 \omega+\frac{\left(y_{2}-y_{1}\right)}{k_{1}} & -\omega & 0 & \cdots & 0 & \cdots & 0 \\
-\omega & 2 \omega+\frac{\left(y_{3}-y_{2}\right)}{k_{2}} & -\omega & \cdots & 0 & \cdots & 0 \\
0 & -\omega & 2 \omega+\frac{\left(y_{4}-y_{3}\right)}{k_{3}} & \cdots & 0 & \cdots & 0 \\
\vdots & \vdots & \vdots & \ddots & \vdots & & \vdots \\
0 & 0 & 0 & \cdots & 2 \omega+\frac{\left(y_{i+1}-y_{i}\right)}{k_{i}} & \cdots & 0 \\
\vdots & \vdots & \vdots & & \vdots & \ddots & \vdots \\
0 & 0 & 0 & \cdots & 0 & \cdots & \omega+\left(1-y_{n}\right)
\end{array}\right]} \\
& \left\{B_{N u}\right\}^{T}=\left[\begin{array}{c}
\frac{y_{2}^{3}-y_{1}^{3}}{k_{1}} \\
\frac{y_{3}^{3}-y_{2}^{3}}{k_{2}} \\
\frac{y_{4}^{3}-y_{3}^{3}}{k_{3}} \\
\vdots \\
\frac{y_{i+1}^{3}-y_{i}^{3}}{k_{i}} \\
\vdots \\
1-y_{n}^{3}
\end{array}\right] \\
& C_{1}=\left(\frac{y_{1}^{4}}{k_{0}}+\sum_{i=1}^{n} \frac{y_{i+1}^{4}-y_{i}^{4}}{k_{i}}\right) \\
& \left\{D_{N}\right\}=\left[\begin{array}{c}
\frac{y_{2}^{2}-y_{1}^{2}}{k_{1}} \\
\frac{y_{3}^{2}-y_{2}^{2}}{k_{2}} \\
\vdots \\
1-y_{n}^{2}
\end{array}\right]
\end{aligned}
$$


Setting the derivative of the $\Delta_{0}$ in Eq. (2) with respect to $y_{j}$ to zero, the optimum locations of outriggers with the objective of minimizing the top-drift can be determined numerically. Comparing to the governing equations expressed by Eqs. (1) and (2), more parameters are considered in the analysis, including the relative rigidities between core-column system and outriggers $(\omega)$, core and column $(\alpha)$, and the parameter about the relative sectional stiffness $\left(k_{i}\right)$. Therefore, more complex and comprehensive structural simulation is developed for the optimum locations of the outriggers.

The governing equations for top-drift can be further extended for various lateral loads. In this paper, two common types of lateral loading cases are considered: (1) triangularly distributed over the height and (2) parabolically distributed over the height. The wind load is commonly modeled with these kinds of distributed load for tall building. The relevant equations are derived. The different lateral loading cases are shown in Fig. 3.

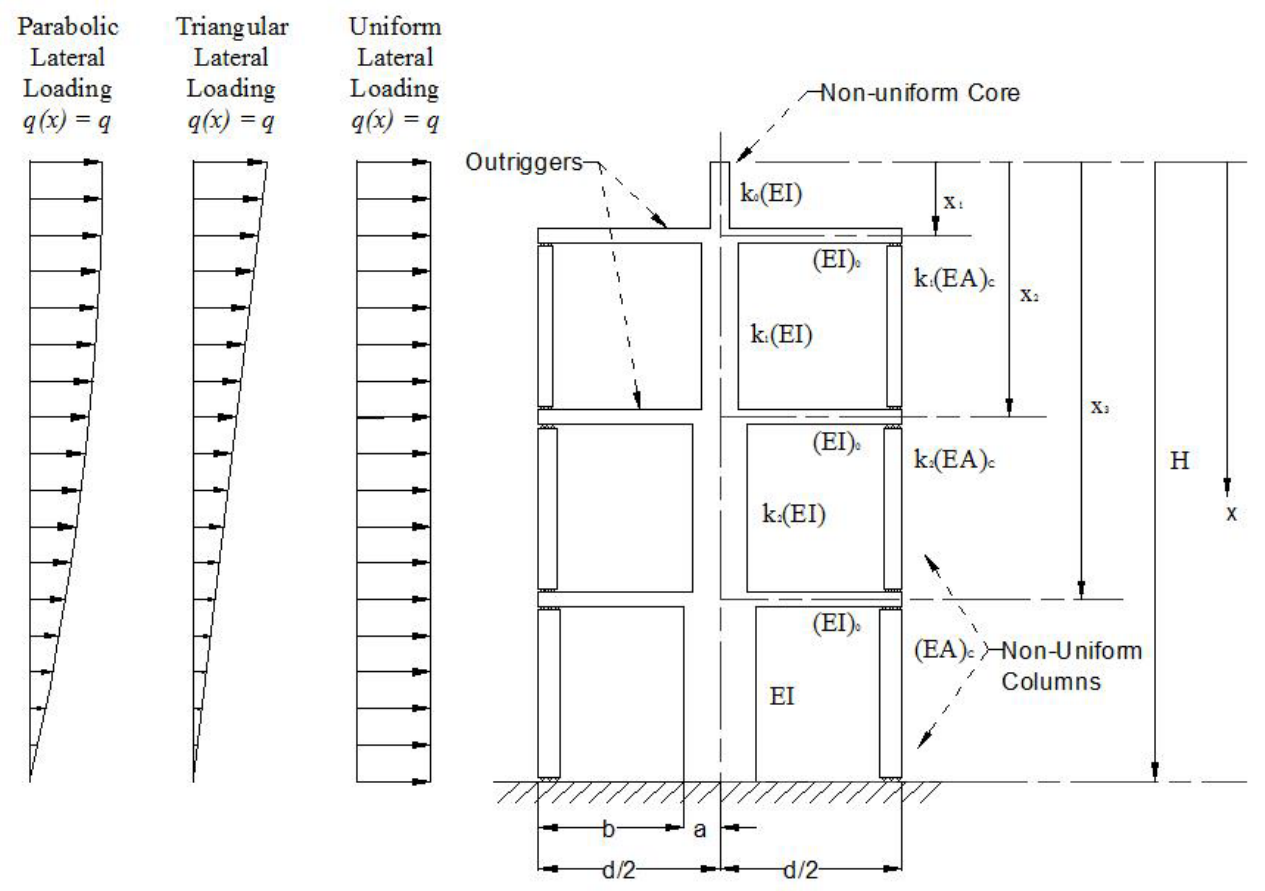

Figure 3. Structure with non-uniform core and columns and different types of lateral loadings

For triangular lateral loading, the top-drift equation is obtained to be:

$\Delta_{0}=\frac{11 q H^{4}}{120 E I}\left(\frac{y_{1}^{4}}{k_{0}}+\sum_{i=1}^{n} \frac{y_{i+1}^{4}-y_{i}^{4}}{k_{i}}\right)-\frac{d H^{2}}{2 E I} \sum_{i=1}^{n} \frac{N_{i}\left(y_{i+1}^{2}-y_{i}^{2}\right)}{k_{i}}=\frac{11 q H^{4}}{120 E I}\left\{C_{1}-\frac{5}{22(\alpha+1)}\left\{B_{N t}\right\}\left[A_{N}\right]^{-1}\left\{D_{N}\right\}\right\}$

where 


$$
\left\{B_{N t}\right\}^{T}=\left[\begin{array}{c}
\frac{4\left(y_{2}^{3}-y_{1}^{3}\right)-\left(y_{2}^{4}-y_{1}^{4}\right)}{k_{1}} \\
\frac{4\left(y_{3}^{3}-y_{2}^{3}\right)-\left(y_{3}^{4}-y_{2}^{4}\right)}{k_{2}} \\
\vdots \\
\frac{4\left(y_{i+1}^{3}-y_{i}^{3}\right)-\left(y_{i+1}^{4}-y_{i}^{4}\right)}{k_{i}} \\
\vdots \\
4\left(1-y_{n}^{3}\right)-\left(1-y_{n}^{4}\right)
\end{array}\right]
$$

For parabolic lateral loading, the top-drift equation is obtained to be:

$$
\Delta_{0}=\frac{20 q H^{4}}{189 E I}\left(\frac{z_{1}^{4}}{k_{0}}+\sum_{i=1}^{n} \frac{z_{i+1}^{4}-z_{i}^{4}}{k_{i}}\right)-\frac{d H^{2}}{2 E I} \sum_{i=1}^{n} \frac{N_{i}\left(y_{i+1}^{2}-y_{i}^{2}\right)}{k_{i}}=\frac{20 q H^{4}}{189 E I}\left\{C_{2}-\frac{9}{200(\alpha+1)}\left\{B_{N p}\right\}\left[A_{N}\right]^{-1}\left\{D_{N}\right\}\right\}
$$

where

$$
\left\{B_{N p}\right\}^{T}=\left[\begin{array}{c}
\frac{-8\left[\left(1-y_{2}\right)^{\frac{7}{2}}-\left(1-y_{1}\right)^{\frac{7}{2}}\right]+35\left(y_{2}^{2}-y_{1}^{2}\right)-28\left(y_{2}-y_{1}\right)}{k_{1}} \\
-8\left[\left(1-y_{3}\right)^{\frac{7}{2}}-\left(1-y_{2}\right)^{\frac{7}{2}}\right]+35\left(y_{3}^{2}-y_{2}^{2}\right)-28\left(y_{3}-y_{2}\right) \\
\frac{k_{2}}{\vdots} \\
8\left(1-y_{n}\right)^{\frac{7}{2}}+35\left(1-y_{n}^{2}\right)-28\left(1-y_{n}\right) \\
\left.\left.k_{1}\right)^{\frac{7}{2}}-\left(1-y_{i}\right)^{\frac{7}{2}}\right]+35\left(y_{i+1}^{2}-y_{i}^{2}\right)-28\left(y_{i+1}-y_{i}\right) \\
\vdots \\
C_{2}=\left(\frac{z_{1}}{k_{0}}+\sum_{i=1}^{n} \frac{z_{i+1}-z_{i}}{k_{i}}\right)
\end{array}\right]
$$




\section{ANALYSIS ON THE OPTIMAL LOCATIONS OF OUTRIGGERS}

Aiming at minimizing the top-drift, the optimum levels of outriggers can be located by solving the nonlinear algebraic equations formulated by setting the derivative of $\Delta_{0}$ in Eqs. (2), (3) and (4) with respect to $\vec{y}$ to zero:

$$
\left\{\begin{array}{c}
\frac{\partial \Delta_{0}}{\partial \mathrm{y}_{1}}=0 \\
\frac{\partial \Delta_{0}}{\partial \mathrm{y}_{2}}=0 \\
\vdots \\
\frac{\partial \Delta_{0}}{\partial \mathrm{y}_{\mathrm{n}}}=0
\end{array}\right.
$$

It is obvious that the equations obtained from Eq. (5) in the case of non-uniform core and columns involve more parameters which greatly influence the analysis for optimum outrigger locations. The non-uniform structure under uniform lateral load is analyzed first. Substituting the matrices into equation with further simplification gives:

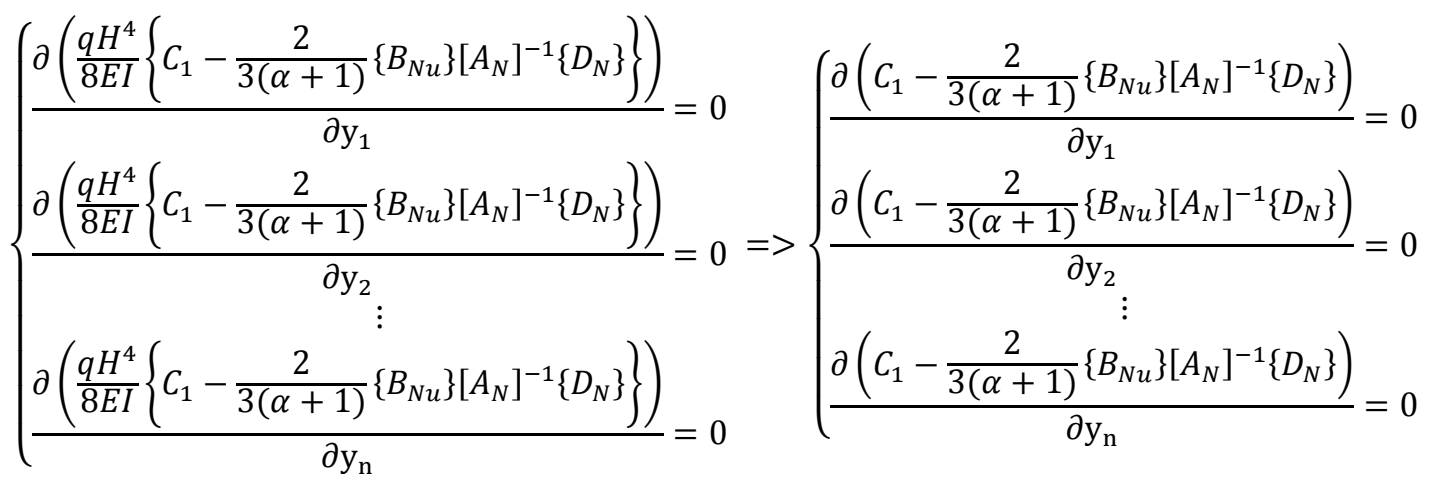

It is found that more parameters can influence the optimum locations of outriggers for the structures with variable cross sections of core and columns, including $\vec{k}$, the parameter about the relative sectional stiffness of core and column; $\alpha$, the flexural rigidity ratio of coreto-column, as well as the parameter $\omega$ and the type of lateral loading.

In the numerical analysis, certain values are assigned to these parameters and some results are obtained and presented in Figs 4-6 in which the results corresponding to different loads are also compared. The results shown in Figs 4-6 are about the optimum locations of outriggers in the structure with three outriggers.: 


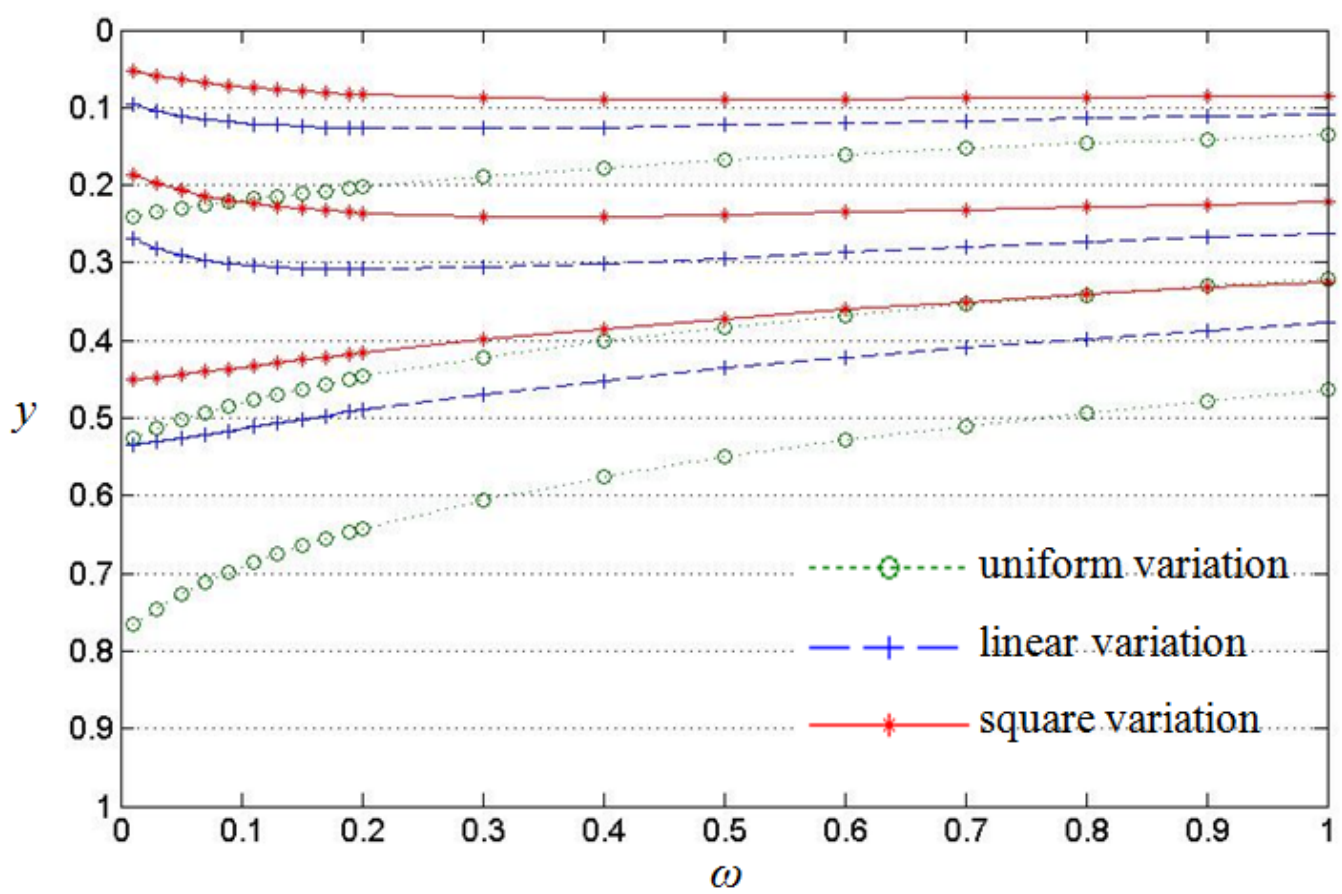

Figure 4. Optimum outrigger locations with different core and columns sections in uniform, linear and square variation under uniform loading $(\alpha=1)$

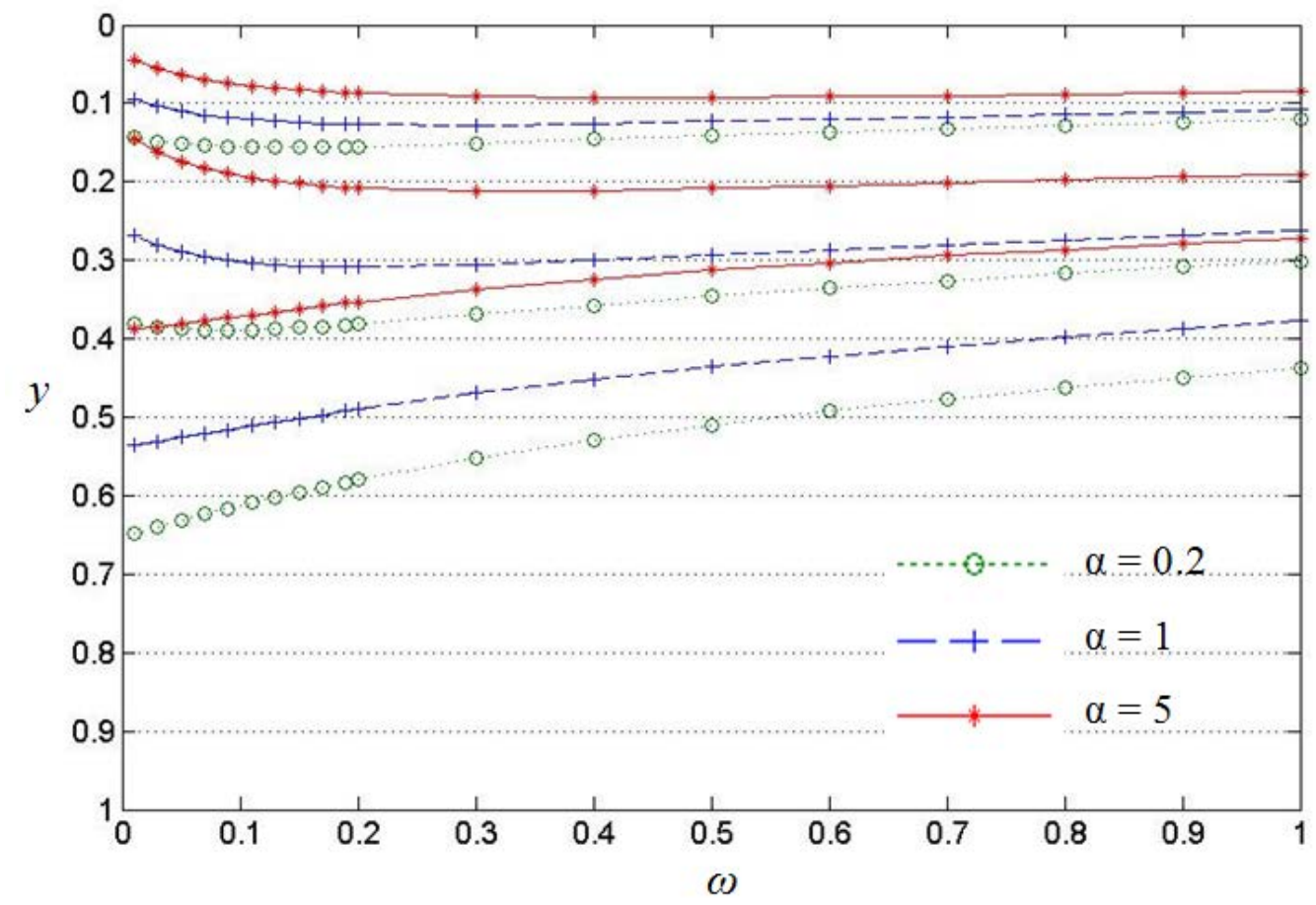

Figure 5. Optimum outrigger locations when the core and column sections vary linearly under uniformly distributed load ( $\alpha=0.2,1$ and 5) 


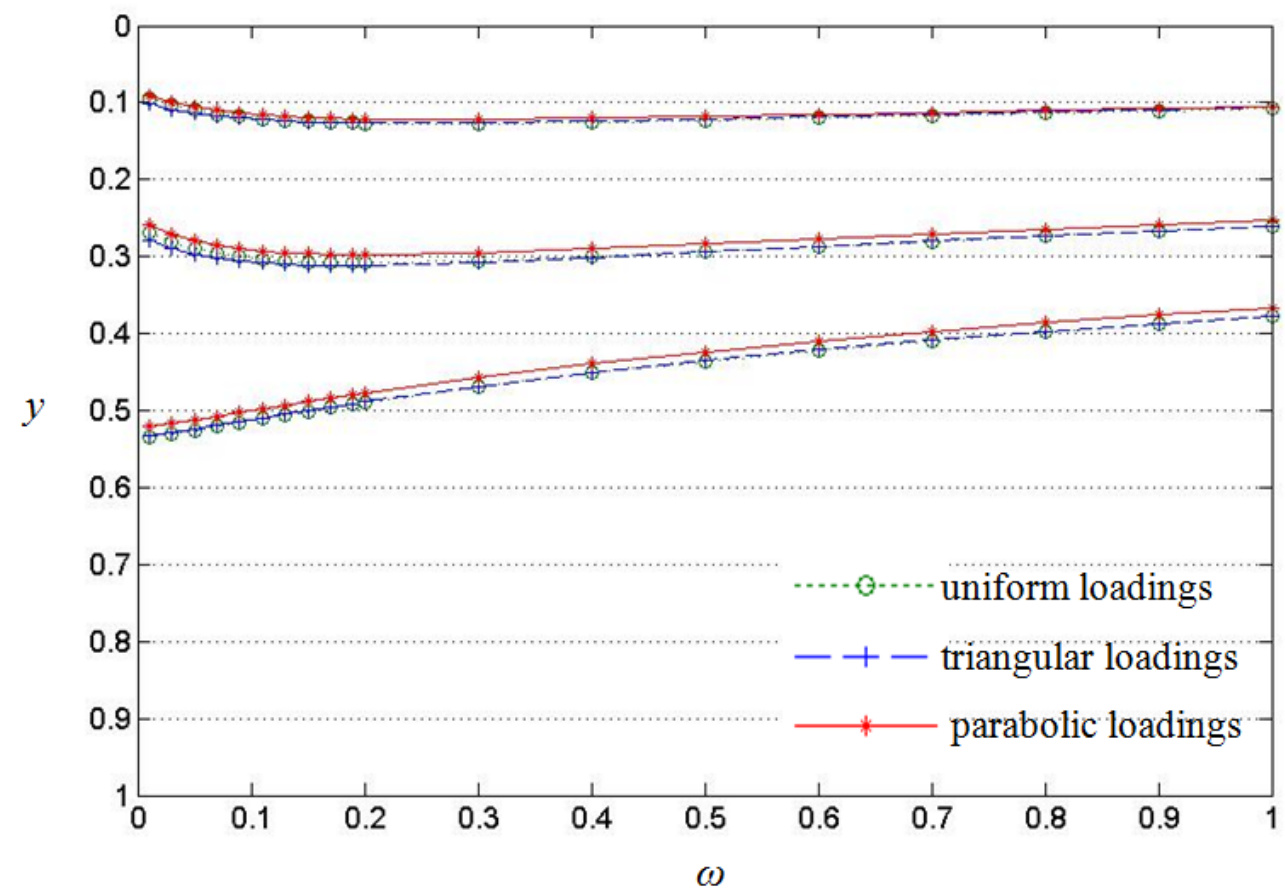

Figure 6. Optimum outrigger locations when the core and column sections vary linearly under different lateral loads $(\alpha=1)$

From the numerical analysis, some significant behaviours are observed and discussed in the following.

1) For more flexible outriggers with bigger value of $\omega$, the following trend of the optimum locations of outriggers is observed. The bottom outrigger location moves upward with a greater slope when $\omega$ is small, and with a flatter slope when $\omega$ closes to 1 . The levels of other outriggers generally linger in a short range (around $10 \%$ of the structure height). On the other hand, the distances between outriggers are gradually reduced.

2) In the aspect of the sectional properties of core-column $(\vec{k})$, higher level of sectional variation induces higher optimum outriggers locations. When $\omega \approx 0$, The outrigger locations are generally higher than or closed to the evenly distributed locations $\left[\begin{array}{ccc}\frac{1}{n+1} & \frac{2}{n+1} & \cdots\end{array}\right]$. When $\omega \approx 1$, the outrigger locations are closed to the second order divided point at $\left[\begin{array}{lll}\left(\frac{1}{n+1}\right)^{2} & \left(\frac{2}{n+1}\right)^{2} & \cdots\end{array}\right]$.

3) Increasing the relative rigidity of core to column with bigger value of $\alpha$, by increasing the core stiffness or reducing the column section stiffness dramatically, the optimum levels of outriggers also move upward as well.

4) It is observed that the difference of optimum outrigger locations is very small for different types of lateral loadings.

In short, the optimum locations are greatly varied between uniform and non-uniform sectional properties, and hence it is necessary to take the change of sectional stiffness of corecolumn into account in the preliminary design for outrigger locations. On the other hand, the assumption of uniform lateral loading is suitable for the preliminary design as the results from the convenient calculation are pretty closed to the ones obtained by other complicated loads. 


\section{DERIVATION OF TOP-DRIFT REDUCTION EFFICIENCY}

The measurement of the influence of the optimum locations of outriggers on the topdrift reduction can be conducted by efficiency analysis. The approach offers quantitative evaluation on the performance of the optimized locations of outriggers. According to [2], reduction efficiency is to express the relative value in percentages of the reduced top-drift or core-moment of the optimized structure and the maximum possible top-drift or core-moment reduction correspondingly when the core and columns work independently.

The term of maximum possible reduction of fully composite behavior of the structure means that the stresses in vertical structural components are proportional to the corresponding distances from their common centroidal axis. In this case, an overall flexural rigidity of the structure with uniform core and columns is given by:

$$
(E I)_{t}=E I+\frac{d^{2}(E A)_{c}}{2}=E I\left(1+\frac{1}{\alpha}\right)
$$

For the structure with variable core and columns, the overall flexural rigidity of vertical components between ith and $(\mathrm{i}+1)$ th outriggers is given by:

$$
(E I)_{t i}=k_{i}\left(E I+\frac{d^{2}(E A)_{c}}{2}\right)=k_{i} E I\left(1+\frac{1}{\alpha}\right)
$$

The structure with $n$ outriggers and under uniform distributed loadings is given for efficiency analysis. The expressions of drift reduction $\left(\Delta_{\mathrm{e}}\right)$ is obtained to be

$$
\Delta_{\mathrm{e}}=\frac{q H^{4}}{8 E I} \cdot \frac{2}{3(\alpha+1)}\left\{B_{N u}\right\}\left[A_{N}\right]^{-1}\{D\}
$$

The following expression for the maximum possible reduction of top-drift is obtained based on the assumption of overall flexural rigidity:

$$
\left(\Delta_{\mathrm{e}}\right)_{\max }=\left(\frac{q H^{4}}{8 E I} \cdot C_{1}\right)-\left(\frac{q H^{4}}{8 E I} \cdot C_{1}\right) \cdot \sum_{i=1}^{n} \frac{k_{i}(E I)}{(E I)_{t i}}=\frac{1}{(\alpha+1)} \cdot \frac{q H^{4}}{8 E I} \cdot C_{1}
$$

As a result, the top drift reduction efficiency is given as

$$
\rho_{\Delta e}=\frac{\Delta_{\mathrm{e}}}{\left(\Delta_{\mathrm{e}}\right)_{\max }}=\frac{\frac{q H^{4}}{8 E I} \cdot \frac{2}{3(\alpha+1)}\left\{B_{N u}\right\}\left[A_{N}\right]^{-1}\{D\}}{\frac{1}{(\alpha+1)} \cdot \frac{q H^{4}}{8 E I} C_{1}}=\frac{2}{3} \frac{\left\{B_{N u}\right\}\left[A_{N}\right]^{-1}\{D\}}{C_{1}}
$$

Similarly, the expressions of the reduction efficiency in the case of triangular and parabolic wind loads can be determined with different parameters and matrix expressions. For triangular lateral loading, the top-drift reduction efficiency is obtained to be 


$$
\rho_{\Delta e}=\frac{5}{22} \frac{\left\{B_{N t}\right\}\left[A_{N}\right]^{-1}\{D\}}{C_{1}}
$$

For parabolic lateral loading, the top-drift reduction efficiency is obtained to be:

$$
\rho_{\Delta e}=\frac{9}{200} \frac{\left\{B_{N p}\right\}\left[A_{N}\right]^{-1}\{D\}}{C_{2}}
$$

For different values of outrigger numbers $\mathrm{n}$, the parameter about the relative sectional stiffness of core and column $\overrightarrow{\boldsymbol{k}}$; the flexural rigidity ratio of core and column $\boldsymbol{\alpha}$, and the type of lateral loadings. The curves of reduction efficiency are shown in the following figures.

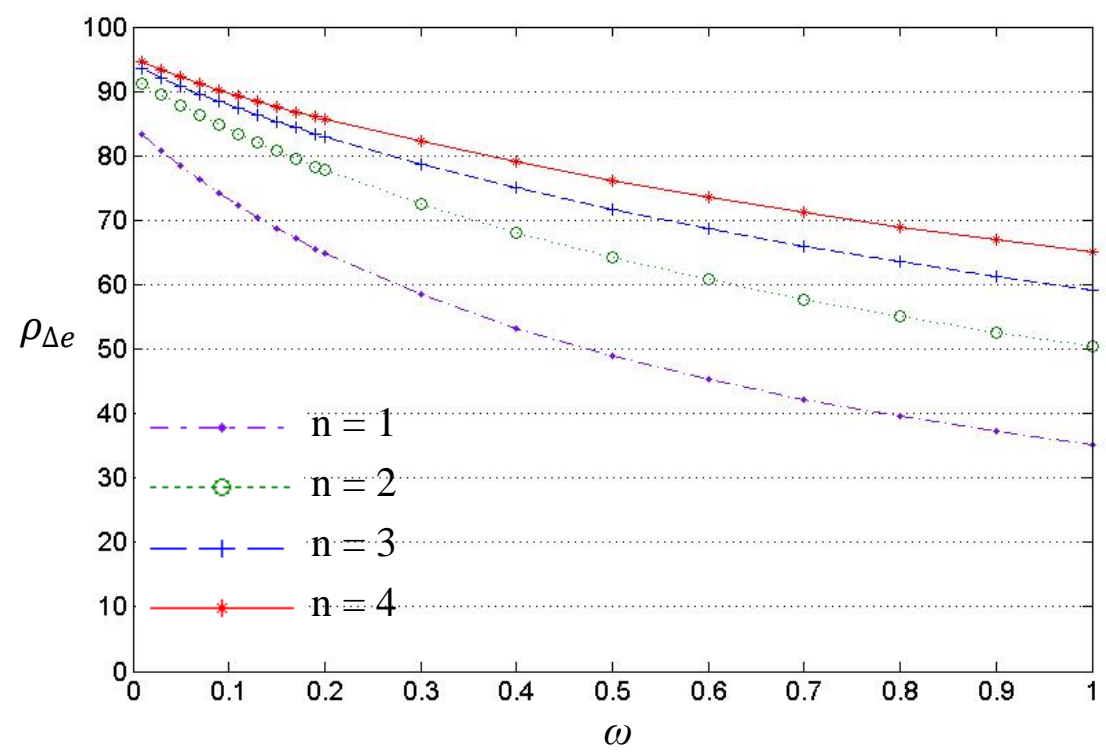

Fig. 7. Drift reduction efficiency for structure with different outrigger numbers ( $\alpha=1, \vec{k}$ in linear variation, uniform loading)

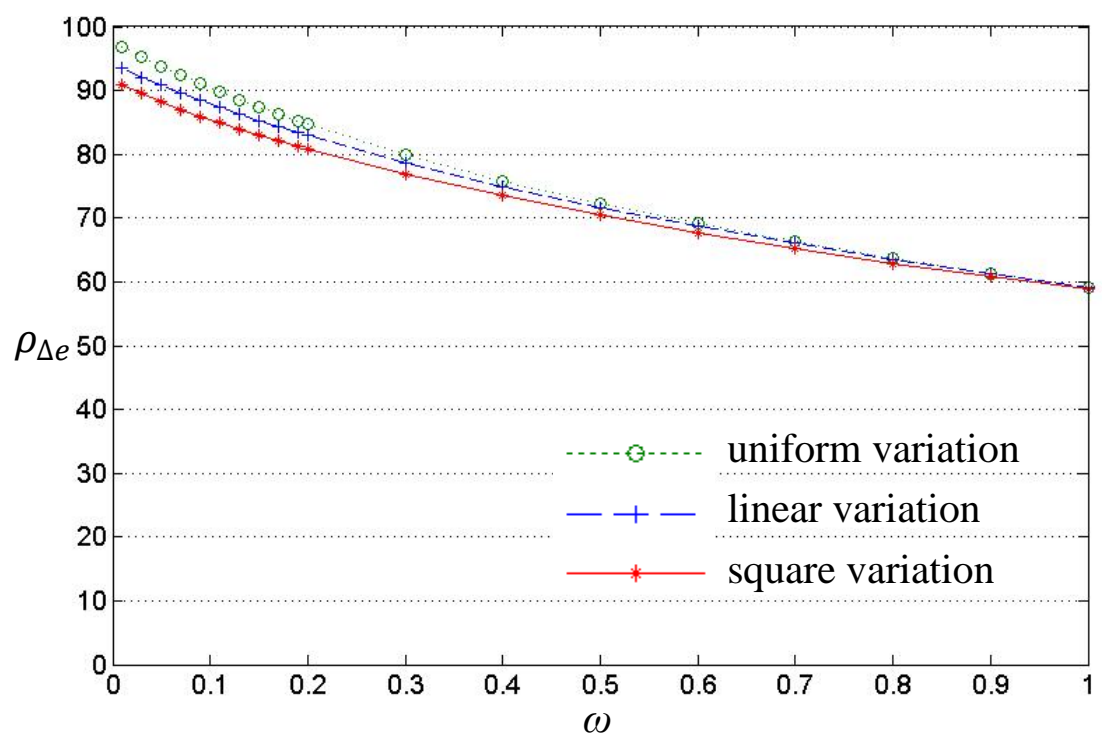

Fig. 8. Drift reduction efficiency for structure with non-uniform core and columns sections in uniform, linear and square variation ( $\alpha=1$, three outriggers, uniform loading) 


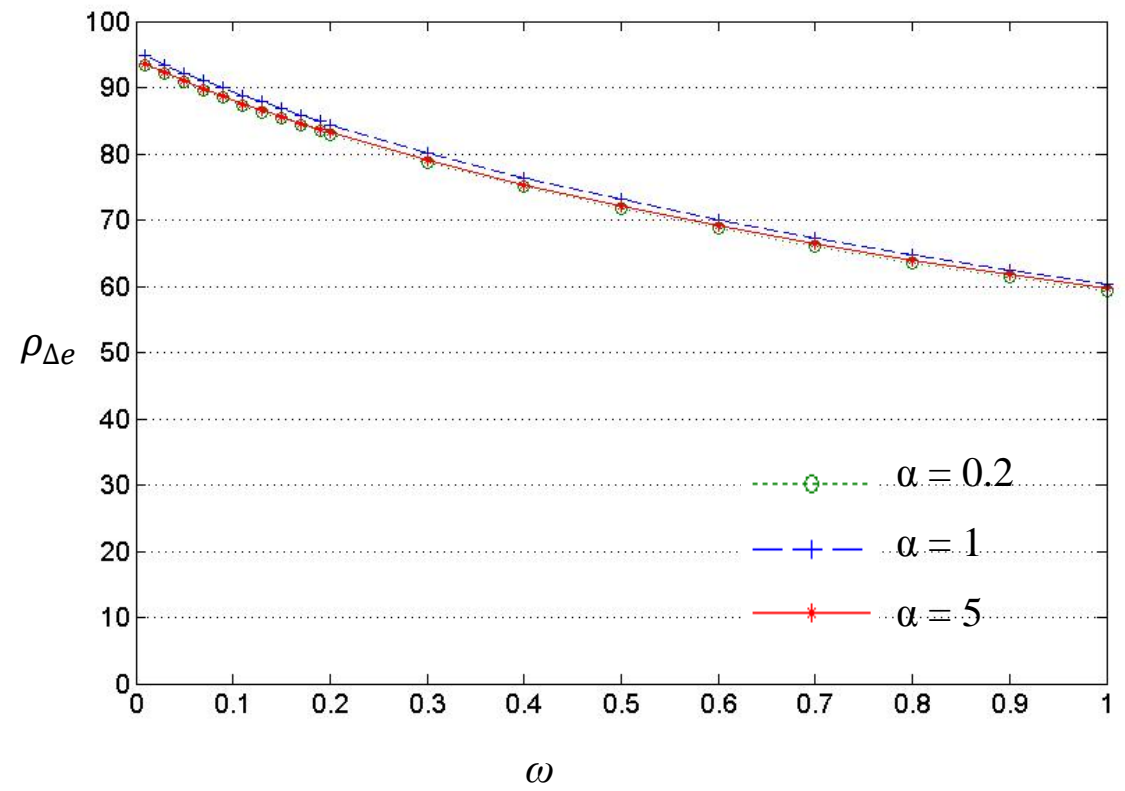

Fig. 9 Drift reduction efficiency for structure with different flexural rigidity ratio of coreto-column ( $\vec{k}$ in linear variation, three outriggers, uniform loading)

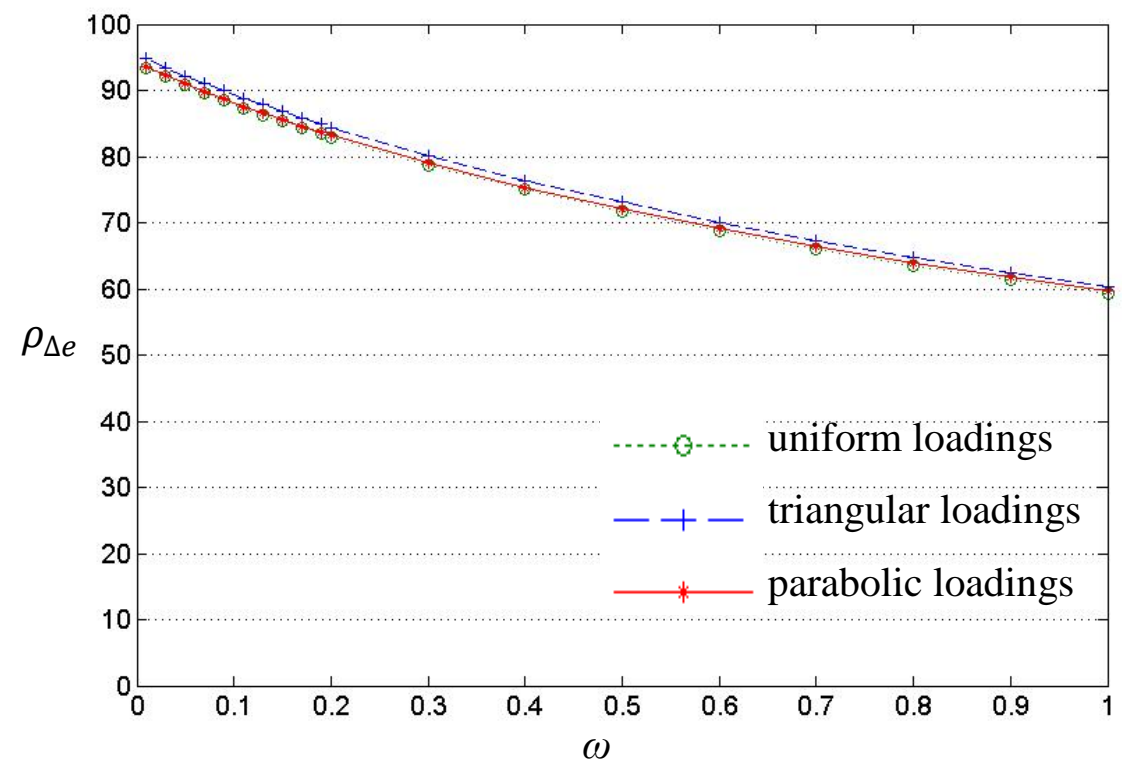

Fig. 10 Drift reduction efficiency for structure under different lateral loadings $(\alpha=1, \vec{k}$ in linear variation, three outriggers) 
From the graphical results of top-drift reduction efficiency in Fig. 7-10, the performance of optimum outrigger locations can be commented as follows:

1) As the number of outriggers in a structure increases when other parameters such as corecolumn sectional property and type of lateral loading remain unchanged, the more reduction in top-drift. However, the diminishing effect applies on the performance of drift reduction that the increments of increase in efficiency reduce for each additional outrigger.

2) When $\omega$, the relative rigidity between core-column system and outriggers, increases, the drift reduction efficiency gradually decreases.

3) The other parameters such as the core-column sectional variation, the flexural rigidity ratio of core-to-column and lateral loadings do not have too much influence on the drift reduction efficiency.

\section{CONCLUSIONS}

In this study, the optimum locations and the behaviour of the outrigger-braced structure with non-uniform core section are analyzed. Compared to the structure with uniform core, the parameters about the relative stiffness of cores and columns at different levels are taken into account and hence more comprehensive analysis is conducted for the reference of real structure design. The influence on the optimum outrigger locations by various parameters are presented and discussed. It is observed that different relative stiffness of the core and columns between different outriggers can influence the optimum locations of the outriggers a lot while the reduction efficiency of top drift is not much influenced.

\section{Acknowledgements}

I am grateful for financial fund from Honours College and Faculty of Science and Technology in University of Macau. Besides, I would like to express my sincere gratitude and appreciation to my supervisors, Prof. ER Guo Kang and Dr. LAM Chi Chiu, for their patience and enthusiastic guidance throughout the research.

\section{REFERENCES}

[1] Er G. K., Iu V. P., "General Procedure of Formulating the Governing Equations for Analyzing Outrigger-Braced Structures". Proceedings of $7^{\text {th }}$ International Conference on Tall Buildings, 589-595, 29-30 October 2009, Hong Kong, China.

[2] Stafford Smith B., Salim I., "Parameter study of outrigger-braced tall building structure". J. Structural Division, 107: 2001-2014, 1981.

[3] Stafford Smith B., Coull A., "Tall Building Structures", John Wiley \& Sons Inc., New York, 1991. 